\title{
CHALLENGES AND CHANGES IN TEACHING PERSON-CENTRED COUNSELLING TO SOCIAL WORK LEARNERS VIA DISTANCE EDUCATION
}

\author{
Desirée de Kock
}

\section{INTRODUCTION}

This article focuses on the quest to be learner-centred in social work training and on the challenges faced by the Department of Social Work at the University of South Africa (UNISA) in teaching person-centred counselling skills to Social Work students via open distance learning. The author first explores the meaning of open distance learning and learnercenteredness, then briefly discusses the theoretical framework supported by the department in teaching Social Work and lastly discusses the strategies used and challenges faced in teaching person-centred counselling skills to Social Work students at UNISA, with recommended changes in addressing these challenges.

\section{UNISA AS AN OPEN DISTANCE EDUCATION INSTITUTION}

In the field of higher education UNISA needs no introduction to social workers in South Africa. UNISA has been teaching and training social work students for the past 68 years. First studying through UNISA was labelled as correspondence and from 1946 until 2003 as distance education (UNISA, nd:5). After the merger between UNISA and the Technikon Southern Africa and the incorporation of VUDEC (the distance education section of the then Vista University) in January 2004, the new UNISA revisited the role of the new institution in South Africa, Africa and globally. UNISA then became a comprehensive tertiary institution, which means that the University offers degrees and diplomas with an academic and vocational focus. The content of most of the degrees offered is academically focused, and that of the National Diplomas has a more vocational focus, with experiential learning as a core component of the qualification (UNISA, 2005:2). Since 2005 UNISA has been known as an open distance learning institution.

What does an "open distance learning institution" mean? This means that UNISA is open to registration for any student who meets the minimum requirements to access the University. Although the profile of UNISA students' has changed from almost all registered students being full-time employed to an increasing number of younger students and students who are not employed (20\%), UNISA is still not a residential university, but presents courses in a distance education mode (UNISA, 2010).

In the establishment of the new institution UNISA formulated its vision as: "Towards the African University in the service of humanity" (UNISA, nd:6). UNISA's commitment to service delivery to students is reflected in the following excerpts from the mission statement that it:

- "provides quality general academic and career-focussed learning opportunities underpinned by principles of lifelong learning, flexibility, and student-centredness;

- is accessible to all students, specifically those on the African continent, and the marginalized, by way of a barrier-free environment, while responding to the needs of the global market" (UNISA, nd:7).

The values supported by UNISA include integrity, social justice and fairness and excellence. The values of social justice and fairness specifically relate to the paradigm of open distance 
learning as it focuses on "promoting equity of access and opportunity so that all may develop their full potential" (UNISA, nd:6).

The UNISA Open Distance Learning Policy document (2008:2) defines open distance learning as "a multi-dimensional concept aimed at bridging the time, geographical, economic, social, educational and communication distance between student and institution, student and academics, student and courseware and student and peers. Open distance learning focuses on removing barriers to access learning, flexibility of learning provision, student-centredness, supporting students and constructing learning programmes with the expectation that students can succeed"

\section{BEING LEARNER-CENTRED IN OPEN DISTANCE LEARNING}

Learner-centeredness within the UNISA context is supported by the following statements in UNISA policy documents:

"Prioritising student needs and basing decisions on student profiles" (UNISA, 2007:3) as well as the statement that learner-centeredness "requires that students are seen as the main foci of the educational process and they are supported to take progressive responsibility for their learning and research. However, the pedagogy employed should enable successful learning through rich environments for active learning; establish links between students' current meaning and contexts and new knowledge to be constructed, and encourage independent and critical thinking." (UNISA, 2008:2)

The Institutional Operational Plan 2010 also specified goals such as the development of:

- integrated student-centred pedagogically sound courseware;

- the integration of pedagogy and technology such as myUnisa and myLife;

- the integrated student-support model;

- the improvement of regional facilities with video-conferencing and satellite delivery services.

The Interim Institutional Operation Plan 2011-2013 also emphasise the crucial need to "improve online learning facilitation through the use of technology" with the aim of having "technological infrastructures with pedagogical capacities fully integrated" by 2013 (UNISA, 2011:10).

\section{THE DEPARTMENT OF SOCIAL WORK, STUDENT-CENTEREDNESS AND OPEN DISTANCE LEARNING}

In this section the focus is on the philosophical and theoretical frameworks taught by the Department of Social work within the open distance learning paradigm and student-centred philosophy of UNISA.

Philosophical and theoretical frameworks

In teaching Social Work in South Africa all universities must meet the exit-level outcomes of the Baccalaureus in Social Work (BSW) qualification as registered with the South African Qualifications Authority (SAQA). At UNISA the Department of Social Work teaches these exit-level outcomes from specific frameworks, namely a postmodernist and constructivist approach, and teaching counselling skills based on the person-centred approach.

The constructivist claim is that people "do not just 'experience' the world objectively or directly" (Moses \& Knutsen, 2007:10). People's experiences are channelled through their 
minds, meaning that people may look at the same thing and perceive it differently. This is influenced by individual characteristics such as age, gender, race and nationality. This is furthermore complicated by social characteristics such as culture and language. Within a constructivist frame of reference we want to capture and understand the meaning of social action for the agent performing it. When something is meaningful or real to the person, it may affect his/her behaviour and have real consequences for the society around this person. For the constructivist there is no absolute truth; the focus is on the experiences of people, how they perceive them and how they contextualise them. The observer forms part of the context of what is happening and there is always an element of subjectivity present (Moses \& Knutsen, 2007:11-12; Terre Blanche \& Durrheim, 2002:6; Zima, 2007:171).

The postmodern paradigm also makes no claim to absolute "truth", and no specific theory or method is better than another in determining the truth. The truth is relative to what the individual or community believes to be true. Therefore social scientists are always linked to their social and historical context and it is not possible to conduct a value-free enquiry into social issues. Furthermore social reality is constructed and social scientific knowledge is a construct of social inquiry. Lastly, social reality always exists as part of human reflection and inquiry (Babbie \& Mouton, 2002:40).

The person-centred approach (PCA) to counselling in Social Work has been the centre of teaching counselling skills at the UNISA's Department of Social Work for the past 13 years. This approach focuses on the self or identity of the person, group or community. "It looks at those experiences that the client cannot allow into his or her conscious mind, because the experiences threaten the client's perception of who he or she is" (Grobler \& Schenck, 2009:4). To deal with these threatening experiences through the PCA to counselling, the social worker as facilitator needs to accept the client and enable clients to see themselves and all of their experiences more clearly. This approach emphasises that the client is the expert about his or her circumstances and not the social worker or facilitator. Each individual perceives their situation differently from they way others do as a result of their own conscious and unconscious experiences, needs, their interaction with the environment and significant others, value systems and many more other factors. In facilitating this process, the focus is on the strengths of the person and not the presented problem. Every individual has their own frame of reference, has to discover their own strengths and determine their self-development. This approach also fits with the constructivist and postmodern theoretical frameworks the Department has adopted. Furthermore, this approach to counselling in Social Work supports the paradigm shift within the social welfare field to deliver social services from a developmental rather than a pathological perspective, as well as to develop the independent functioning of individuals, groups and communities (White Paper for Social Welfare, 1997).

\section{Student-centeredness in the Department of Social Work}

To ensure that our training is student-centred, supportive and empowering in nature, several research studies were conducted. Research done by Lintvelt (2008:29-31, 45, 50) provided the Department of Social Work with the following profile of our students:

- The majority of the UNISA students are female;

- In the $4^{\text {th }}$ year the majority of the students are between 31 and 35 years old;

- The majority (75\%) are involved in a special relationship;

- The majority (53\%) have their own children; and 
- The majority grew up with their own parents, who were employed.

The living conditions of students during their studies at UNISA are characterized by the following features:

- Poor housing;

- Being victims of crime;

- Household responsibilities;

- Very difficult financial conditions;

- Concern about low remuneration; and

- Burden of study loans (Lintvelt, 2008:87 ).

Wade (2009) conducted a study pertaining to trauma experiences of 98 fourth-year students in 2006 and 124 fourth-years in 2008; these were students studying Social Work at UNISA. Some of her key findings were:

- The highest number of experiences of traumatic events by one students was 32 ;

- The lowest experience of traumatic events by a student was one;

- The average experiences of traumatic events is 13 ; and

- The majority of students experienced between six to 16 traumatic events (Wade, 2009:338).

The challenge of growing student numbers

When social work education was introduced at UNISA in 1942, it formed part of the Department for Sociology and Criminology. The Department of Social Work was established in 1960 (Van Dyk, 2009). Thirty years later, in 1990, we had 80 first-year learners, and by 2007 that number had grown to 5 697. The increase in student numbers per module is as follows:

TABLE 1

RANGE OF STUDENT ENROLMENTS FOR SOCIAL WORK MODULES IN 2010 - 2011

\begin{tabular}{|c|c|c|c|c|}
\hline $\begin{array}{l}\text { Academic } \\
\text { year level }\end{array}$ & $\begin{array}{c}\text { Range of registra- } \\
\text { tions in } 2010\end{array}$ & $\begin{array}{c}\text { Range of registra- } \\
\text { tions in 2011 }\end{array}$ & $\begin{array}{c}\text { Practical module } \\
\text { enrolments 2010 }\end{array}$ & $\begin{array}{c}\text { Practical module } \\
\text { enrolments 2011 }\end{array}$ \\
\hline First year & $3202-3965$ & $3926-4811$ & 3202 & 3926 \\
\hline Second year & $1340-3000$ & $1905-2326$ & 1417 & 2326 \\
\hline Third year & $727-992$ & $726-1131$ & 1494 & 1447 \\
\hline Fourth year & $261-421$ & $291-393$ & 862 & 919 \\
\hline TOTAL & 30526 & 33664 & 6975 & 8618 \\
\hline
\end{tabular}

In teaching Social Work at UNISA the lecturing staff (11 full-time staff members, including the Head of the Department) teaching the undergraduate students are also responsible for the development of the study material to guide and support students through their learning process. There are no lectures and therefore these study guides must be of such a nature and quality that they guide the student through the prescribed book(s) and the understanding of the theory as well as the development of practical skills they need to apply in practice after their graduation. Six of these staff members, with the assistance of an additional four full-time staff members, are also responsible for the supervision of postgraduate students in Social Work. 
"The Department of Social work strives to promote the ideals of democracy, social transformation and social justice. We aim to practically apply the fundamental principle of the University of South Africa's vision, namely to be 'in service of humanity'. Our teaching strives towards academic excellence and relevance congruent with the ethos of the profession of Social Work and within the parameters of the Act on Social Service Professions (Act 110 of 1978 as amended). Our training is student-centred, supportive and empowering in nature" (Social Work, 2010). In adhering to the nature and demands of open distance learning we facilitate the study process for our learners by sending them study guides, tutorial letters and DVDs, which they use in conjunction with the prescribed books they have to buy. The lecturers are a telephone call away and can also be contacted via e-mail or the myUnisa online student portal. The Student Support Unit, in cooperation with academics, appoints tutors who assist learners at the first- and second-year levels by presenting face-to-face classes. In some modules lecturers also arrange discussion classes and workshops, which bring them into face-to-face contact with the learners.

Although open distance learning has its own challenges, it is in particular the increase in student numbers in the practical modules which poses a challenge to the Department.

\section{TEACHING PERSON-CENTRED COUNSELLING TO SOCIAL WORK LEARNERS VIA DISTANCE EDUCATION}

In this discussion the author briefly refers to the contribution of the theoretical modules, but focuses on the teaching of these skills in the practical modules.

\section{CURRENT EDUCATION AND TRAINING OF THE PERSON-CENTRED APPROACH (PCA)}

First year of study

In the first year of study learners have three compulsory social work modules, namely Welfare Policy (SCK101W), Introduction to Social Work and the Helping Process (SCK102X), and Social Work Practica (SCK103Y).

Apart from being given a historical and chronological overview of the development of social welfare and social work in South Africa, and being introduced to the most important policies and legislation frameworks, learners are introduced to the vision of development and empowerment in South Africa. In this regard, Van Dyk (2006) refers to the concept of ubuntu and the connection between ubuntu and the person-centred approach, as well as to the philosophy inherent to the person-centred approach. These concepts are explained to the learners by connecting person-centeredness with being people-centred, and they are illustrated with reference to the realities in South Africa.

In the module Introduction to Social Work and the Helping Process, learners are introduced to the theory and philosophy inherent in the person-centred approach to counselling (helping), the values and ethics in social work, and how the two connect with each other. Learners are introduced to basic concepts such as congruence, unconditional positive regard, empathy and personal power, which are further explained by using real-life scenarios and case studies (Van Dyk, 2000).

In the module Social Work Practica learners have to compile a portfolio. In preparing the portfolio they have to study sections B and C in their prescribed book by Grobler and Schenck, 
Person-centred facilitation: Process, theory and practice (2009). These sections deal with the facilitator's values and putting thinking and values into practice (Mbedzi, 2009a).

In the portfolio learners have to apply their knowledge through the following activities:

- substantiating social work as a career choice, describing the characteristics of a good social worker and describing their own characteristics;

- compiling a community profile by identifying general resources, welfare organisations, groups and people with influence, social, cultural and religious differences, and welfare issues in the community;

- writing down their own thoughts about child abusers, religious beliefs, non-believers and gender issues such as the election of males as presidents - and thereafter identifying their own prejudices, stereotyping and discriminatory thoughts around these issues;

- learning about the value and belief systems of other people and experiencing different frames of reference by exposing themselves to a group with a different belief system than their own, or by visiting a place they would normally not visit and documenting their experiences (Mbedzi, 2009b).

During each academic year the Department of Social Work arranges three discussion classes for learners who are enrolled for the practical module. The aims of these discussion classes are to discuss the activities for the portfolio, the values of the facilitator and facilitation skills. Because of the large number of learners registered for this module, the discussion classes are not compulsory. In addition to the 9344 registrations for the theory modules, 3926 learners registered for Social Work Practica in 2011. These portfolios are all assessed and count towards the students' examination mark for SCK103Y.

Second year of study

Six modules are presented in the second year of Social Work, and learners have to choose five. The modules are:

- Facilitating Communication with People in Groups and Communities (SCK2013);

- Practical Guide to Facilitating Communication in Groups and Communities (SCK2024);

- Welfare Policy (SCK2035);

- Life Tasks, Obstacles and Resources and Competence (SCK2046);

- Marriage Guidance: Facilitative Couples Counselling (MGG201W);

- Sexual Trauma (MGG202X).

The module Facilitating Communication with People in Groups and Communities focuses specifically on introducing the learners to the theory of the person-centred approach in counselling. Although the focus is on groups and communities, reference is also made to working with individuals. Learners have to study the basic PCA concepts, the 19 propositions, and be able to apply these propositions to group work and community work situations. We also focus on values, ethical issues and the basic skills in the person-centred approach. The study guide gives examples to learners in the format of scenarios and case studies. Empowerment, the fact that the community/group/person is the expert on their circumstances, and the personal strength of the client are emphasised (Mohapi \& Schenck, 2006a). The prescribed books which focus on the PCA for this module are: 
- Grobler, H. \& Schenck, R. 2009. Person-centred facilitation: Process, theory and practice $\left(3^{\text {rd }}\right.$ ed). (This book is prescribed from the first to the fourth year of study.)

- Tolan, J. 2003. Skills in person-centred counselling.

In the module Marriage Guidance: Facilitative Couples Counselling the learners are introduced to a number of theories used in counselling. However, special attention is given to the PCA, because in the Department of Social Work at UNISA we believe that this is an approach that embraces, firstly, the values and beliefs needed for people to take control of their own lives, and secondly, the principles of empowerment and development (Petty, 2006).

Up to this point the focus has been on the theory in the education and training of social work learners. The Practical Guide to Facilitating Communication in Groups and Communities focuses on teaching learners how to apply the PCA; to learn how to create the conditions for person-centred counselling, and to learn the basic skills in working with symbolised experiences such as attending, listening, probing and empathy. Learners also have to integrate their theoretical understanding of the 19 propositions and identify how these apply in practice in working with groups, communities and ultimately individuals. Apart from the more than sixty activities in the workbook that the learners have to work through, until 2009 this was taught through a total of four to five workshops with the learners, conducted over a period of five months (a total of 12 days). The learners work in groups and practise the basic skills through role plays, case scenarios and observation exercises. They also have to compile a portfolio based on the activities given in the workbook and additional activities given to them by the workshop supervisors. The learners are also introduced to advanced skills such as advanced empathy and immediacy (De Kock, 2009; Mohapi \& Schenck, 2006b).

For 2009 we had 916 learners registered for this course, of whom 12 resided outside the borders of South Africa. The workshops were conducted by 37 workshop supervisors at 17 centres in South Africa and one workshop supervisor in Gaborone, Botswana. The ideal number of learners allocated to a workshop supervisor should be 12 to 15 . However, because of the large number of learners and the limited number of workshop supervisors as well as the limited physical resources, the average ratio of workshop supervisor to learners in 2009 was 1:20. Of the 46 workshop sessions presented by the 38 workshop supervisors, only 10 groups have 15 or fewer learners attending. This increase in numbers challenged the human and physical resources available to the Department of Social Work.

During 2009 the Practical Guide to Facilitating Communication in Groups and Communities was reworked and in 2010 students received a Workbook to Facilitate Communication in Groups and Communities as Tutorial Letter 501 of 2010 (De Kock, 2010). In the workbook activities are linked with what students had to do in their first year and the activities were constructed in such a way that students could complete them on their own. Therefore no workshops were presented. The students had to complete the workbook activities and submitted it as a portfolio of evidence of their understanding and application of the PCA in counselling. All these portfolios were marked and counted towards the students' examination mark.

Third year of study

In the third year the Social Work curriculum consists of five social work modules, apart from their second major (Psychology, Criminology, Philosophy or Anthropology). These are:

- Social Casework (SCK3016);

- Theory, Values and Skills for Work with Groups and Families (SCK3028); 
- Community Work (SCK3039);

- Guidelines for Practical Case, Group and Family Work (SCK304A);

- Community Work Practicals (SCK305B).

At this level learners learn in depth about the social work methods relating to casework, group work and community work. They also learn how to apply the PCA to counselling in these methods. The first three modules mentioned are theory-based and the theory is put into practice for the learners by making use of examples and case studies (Grobler, 2009a; Grobler, 2008a; Louw \& Dicker, 2001).

In the practical modules the basic skills learned in the second year are revised, and advanced counselling skills such as advanced empathy and immediacy in working with unsymbolised experiences are added. The compulsory requirements for the Case, Group and Family Work module at this level are as follows:

SCK304A Case, Group and Family Work:

- One half-day orientation session;

- Three 3-day workshops (full day)

- Five half-day group supervision sessions;

- One half-day evaluation session;

- One half-day practice session (Grobler, 2009b).

The integration of theory, values and skills is a central part of the practical work in the third year. In the abovementioned workshops the learners work with the workshop supervisors to reach this integration through role play, case studies and simulated situations. The content of the workshops includes working with individuals, families, children, groups and statutory work from a person-centred perspective. During the group supervision sessions, attention is also paid to adults and children in different and challenging situations, which range from experiencing medical difficulties such as losing a limb to abuse and crime-related and work-related issues. Attention is also given to various difficulties the social worker may encounter.

The aims of the module Case, Group and Family Work are that learners "will be able to understand and apply, in simulated situations with individuals (both adults and children), the following themes:

- the person-centred theory (the 19 propositions of Rogers)

- the values associated with the theory

- the skills (both basic and advanced) of the person-centred theory

- assessment and evaluation as part of the process of facilitation

- innovative ways of relating to and communicating with people

- awareness of and exploration of the development of your own professional self as facilitator" (Grobler, 2008b).

The Department of Social Work appointed about 35 workshop supervisors to assist the fulltime staff member who is responsible for the workshops and supervision of learners across the country. The ideal workshop supervisor to learner ratio is $1: 8$, but because of the fact that more than 753 learners registered for this module this year, the average ratio is 1:21. Many of our workshop supervisors in Durban, Johannesburg and Pretoria are responsible for more than one group of learners. 
The compulsory requirements for the Community Work module at this level are as follows:

SCK305B Community Work:

- One full-day orientation session;

- One 3-day workshop (full day);

- Two 2-day workshops (full day);

- One half-day evaluation session;

- Tasks, including workbook and portfolio activities (Grobler, 2009b).

The practical activities in community work entail a visit to an organisation which renders community services, the arrangement and execution of an awareness walk, creating a product/poster relating to participatory community development, compiling a community profile, as well as identifying the presence or absence of PCA behaviour and the propositions in videos or movies. This is also done through group activities and role play, under the supervision of the appointed workshop supervisors (Skhosana, 2009). The learners have to write reports on all their activities. In 2011 the Department of Social Work appointed approximately 35 workshop supervisors to assist the full-time staff member who is responsible for the workshops and supervision of the 710 learners across the country. Again, the ideal workshop supervisor to learner ratio is 1:8, but because of the large number of learners registered for this module the average ratio is 1:20. Here, too, many supervisors are responsible for more than one group of learners.

Fourth year of study

In their final year of study the curriculum consists of social work modules only. In the fourth year learners have to enrol for the theory and practical modules simultaneously. Because many of our learners are working while they are studying and have responsibilities as life partners and parents too, we advise them to complete the fourth year over at least two years. The theory, and especially the practical work, demands much from them and very few learners are able to complete all ten modules in one year.

The curriculum for the fourth year entails the following:

- Casework: work with individuals, couples and families (SCK401A) plus the practica (SCK402B);

- Group work: work with children, youth and adults (SCK403C) plus practica (SCK404D);

- Community work: the planning (SCK405E) and execution of a project (SCK406F);

- Social work management: the organisation (SCK407G), the employee and the manager (SCK408H);

- Research project: project planning and execution (SCK410B);

- Statutory work, ethics and supervision (SCK411C).

The level 4 practica are compulsory and are presented continuously from January to September each year. Besides being placed in an organisation, learners must attend regular workshops and supervised sessions. The process of placing learners with organisations to conduct the required practical work in their fourth year already begins in September the previous year. In January learners have to attend a full-day orientation workshop for the theory modules. At the end of January or beginning of February learners have to attend a block period of five days at the organisation where they are placed for their practica to get to know the organisation and 
undertake tasks. Besides this, learners have to spend at least eight hours per week at the organisation from February to the end of September in the year they are registered for practical work (Botha, 2009; Schenck, 2002; Schenck, 2009).

Learners registered for SCK402 (Casework) also have to attend three sets of two-day workshops, each of which focuses on working with individuals (adults, children) families, and on statutory work. Learners have to conduct at least 20 interviews while working with individuals, and must conduct at least one interview with a family after the second workshop. Learners have to work with one or more clients, depending on the needs of the client/s. The interviews may not be 20 once-off interviews. Telephone interviews are recorded as contacts, but do not count as part of the 20 interviews. Process notes must meet the prescribed requirements, which include the identification of the propositions that emerge during the interview and the skills applied during the interview.

Learners registered for SCK404D (Group Work) have to apply the social work group work processes and conduct eight group sessions (including the termination session) with adults or children. The learners also have to attend 51/2 workshop days scheduled from February to July each year. Again, with the group work they have to complete the required process notes, which have to reflect the group processes and interactions, the skills applied during the group sessions, and the related PCA theory (Buthelezi, 2002; Mohapi, 2009).

Learners registered for SCK406F (Community Work) have to apply the community work processes and conduct a community project, starting with making contact and building relationships, and then engaging the community in planning, executing and sustaining the project. They also have to attend five workshops scheduled from February to July each year (eight days altogether). With the community work, too, learners have to complete the required community work report, which has to reflect all the processes and interactions, the skills applied during the engagement with the community, and the related PCA theory (Du Plessis \& Louw, 2009).

Apart from the above, learners also have to attend supervision sessions with their supervisors from February to August. Learners are also expected to be involved with other activities required at the organisation where they are stationed, such as intake work and attending case conferences and staff meetings (Schenck, 2009). During May/June the three assigned lecturers in the Department of Social Work are involved with the half-year evaluations of the fourth-year learners and during September each year the final evaluations are done. These three lecturers responsible for these modules are assisted by the other full-time staff in the Department to do the assessments of the 291 learners registered for Casework; the 283 learners registered for group work; and the 345 learners registered for Community work. The learners have to submit a portfolio for each of the practical modules done during the year, and they have to prepare a 5minute presentation for the final evaluations. The supervisor and the contact person at the organisation have to report to the University about the functioning, progress and competence of each learner. The lecturer based in Durban is responsible for the assessment of the learners who conduct their practical work in KwaZulu-Natal. This included 180 learners for 2010 and 240 for 2011.

The ideal supervisor to learner ratio is 1:5. However, with an average of 306 learners in the practical modules and five lecturers and 40 supervisors involved with the supervision of the learners, it is no longer possible for us to realise the ideal ratio. This applies specifically to the 
areas with a higher learner population density such as Pretoria, Johannesburg, Durban and Polokwane.

Although the module Social Work Supervision and Ethics does not have a practical component, the theory, values and principles of the PCA are integrated in the presentation of this module (Van Dyk \& Harrison, 2008).

During 2007 Lawlor did research in determining the views of students, supervisors and the contact persons at organisations where students are placed for their fourth-year practical work. Lawlor $(2008: 61,83,95)$ reported the following findings in this study:

Student views:

- The majority (83\%) of the students who studied at UNISA stay in the profession;

- Seventy-two per cent $(72 \%)$ of the students are of the opinion that their education and training in Social Work at UNISA do equip them for practice; and

- They have a positive perception about the placements settings for their fourth year practical work.

The majority (61\%) supervisors indicated that the professional development and skills of UNISA Social Work students are better or the same as those of students from other universities. The contact persons at the organisations indicated that the behaviour of UNISA students with reference to punctuality is the same as those of students from other universities and $62 \%$ were of the opinion that the skills of the UNISA social work students are better or equal to those of students from other universities.

In his research Mbedzi (2010:21) indicated that there are no follow-up studies done in relation to the integration of theory by professional social workers. The only studies available were done in relation to fourth-year students. Mbedzi conducted his study with Social Workers who studied at UNISA and how they integrated PCA into practice. He also found that the majority of students who studied at UNISA utilise the PCA when they work as social workers. However, many of them do experience challenges due to high case loads, the expectations of organisations related to specific programmes or results as understanding and implementing PCA as a way of being and not only as a counselling approach (Mbedzi, 2010:74). The researcher is of opinion that this difficulty has a direct link with the challenges experienced in dealing with high student numbers which is indicated in this article.

\section{FUTURE EDUCATION AND TRAINING OF SOCIAL WORK LEARNERS IN THE PERSON-CENTRED APPROACH}

In this section the author focuses on current developments and recommendations for the future education and training of social work learners at UNISA.

Current developments

Taking into account the sharp increase in the number of learners registering for the BSW qualification over the past five years (with the number of learners increasing from 480 to 2326 in the second year; from 300 to 1447 in the third year, and from about 100 to 919 learners in the fourth year), the lecturers at the Department of Social Work had to revisit and rethink the format in which the practical modules are presented. The logistics around the management of the number of supervisors (170 in 2011) and venues available for workshops had become a real challenge. 
As previously indicated, the presentation of the practical module in the second year has already changed and the performance of these students in the examinations as well as their adjustment in their third-year practical work will indicate the success of these changes, which will only be known at the end of 2011.

The curriculum is still under review and the presentation of the practical modules for the third and fourth year is still under scrutiny. The Institutional Operational Plan of UNISA lists several of the objectives, such as:

- the development of integrated student-centred pedagogically sound courseware;

- the integration of pedagogy and technology (myUnisa \& myLife);

- the development of an integrated student-support model;

- the improvement of regional facilities, including video-conferencing and satellite delivery services, that will also enable the Department of Social Work to increase the effectiveness of the practical training offered to learners.

To innovatively manage the increase in student numbers and to decrease the distance in open distance learning we have to use technology to our advantage in teaching Social Work Practice at UNISA.

The increase in student numbers and limited resources for the placement of fourth-year students also called for innovative thinking from the Department. At the beginning of 2009 the Department of Social Work, under the leadership of Professor Rinie Schenck, started with a project called the "Bright Site of Sunnyside". This project developed into a service learning site for fourth-year Social Work students, where they have the opportunity to conduct their practical work under the supervision of supervisors and they can also conduct their research projects in Sunnyside. It also serves as a centre delivering services to the community with the involvement of other departments at UNISA. This service learning site has expanded from accommodating 9 learners in 2009 to 25 in 2010 and 50 learners in 2011.

It is envisaged that the Department will expand this project to other major centres in South Africa and that these projects will be registered as non-profit organisations, from where we shall be able to supervise the practical work of the fourth-year learners and render greater social work service to the community. The ground work for such a project in Durban is already well on its way.

\section{RECOMMENDATIONS}

The Department of Social Work at UNISA is facing challenges related to the increase in student numbers; the reality of limited human resources (supervisors) to teach PCA skills to the social work students; limited physical resources to accommodate the large student numbers; and the limitations in the placement of fourth-year learners for practical work. Taking into consideration the commitment of UNISA to be the African University in the service of humanity and open distance learning, the following recommendations are made:

- The expansion of the "Bright Site" projects to all provinces in South Africa, especially provinces such as the Northern Cape, Mpumalanga and Limpopo, where there is a general lack of resources and learners often move to Gauteng to complete their fourth year of study;

- The maximum use of video-conference facilities (when upgraded by UNISA) to teach PCA skills to social work learners at second- and third-year level; 
- The development of a Postgraduate Certificate of Social Work focusing on PCA. This will increase the human capacity of supervisors for UNISA and enable any social worker to upgrade his/her counselling skills.

\section{CONCLUSION}

The Department of Social Work at UNISA introduces learners to various approaches to counselling in social work. However, our training focuses specifically on teaching learners the theory and practice of person-centred counselling in social work. From this discussion it is clear that the Department of Social Work has experienced numerous challenges in the management of the practical teaching of its learners. We have to ensure that learners understand the theory of person-centred counselling and are competent in applying the skills before they are exposed to working with clients in their final year of study. Although they are supervised by an experienced social worker, and are monitored by another social worker who acts as a contact person in the organisation, it is still the responsibility of the Department of Social Work at UNISA to ensure that we place competent learners with these organisations, and that they adhere to the ethics, norms and standards for student social workers as prescribed by the South African Council for Social Service Professions.

The aim of the current re-curriculation process is to enhance the theoretical and practical competency levels of learners at the end of their third year of study, which will enable us to deliver even more competent learners to the final year of study and improve the quality and quantity of social workers entering practice. However, with an average pass rate of $75 \%$ in 2007; 82\% in 2008 and 77\% in 2009 (UNISA Examinations, 2009) and the reality that the Department of Social Work at UNISA delivers about $70 \%$ of the social workers practising in South Africa (Schenck, 2008), somewhere UNISA must be doing something right!

\section{REFERENCES}

BABBIE, E. \& MOUTON, J. 2002. The practice of social research. New York: Oxford University Press.

BOTHA, P. 2009. Dates and venues for workshops and practice sessions; assignment dates. Tutorial letter 301/2009 for SCK4009. Pretoria: University of South Africa.

BUTHELEZI, R.T. 2002. Social group work with adults: integrating theory and practice. Only study guide for SCK404D. Pretoria: University of South Africa.

DE KOCK, D. 2009. Curriculum, tutorial matter, assignments and practica. Tutorial letter 101/2009 for SCK2024. Pretoria: University of South Africa.

DE KOCK, D. 2010. Workbook to facilitating communication in groups and communities. Tutorial Letter 501/2010 for SCK2024. Pretoria: University of South Africa.

DU PLESSIS, C. \& LOUW, H. 2009. Guide for community work workshops and practicals. Tutorial letter 501/2009 for SCK406F. Pretoria: University of South Africa.

GROBLER, H. 2008a. Theory, values and skills for work with groups and families. Tutorial letter 501/2009 for SCK3028. Pretoria: University of South Africa.

GROBLER, H. 2008b. Guidelines for practical casework, group and family work. Tutorial letter 501/2009 for SCK304A. Pretoria: University of South Africa.

GROBLER, H. 2009a. Social casework. Only study guide for SCK3016. Pretoria: University of South Africa. 
GROBLER, H. 2009b. Dates for workshops, practice and group supervision sessions. Tutorial Letter 102/2009 for SCK304A \& SCK305B. Pretoria: University of South Africa.

GROBLER, H. \& SCHENCK, R. 2009. Person-centred facilitation: process, theory and practice $\left(3^{\text {rd }} \mathrm{ed}\right)$. Cape Town: Oxford University Press Southern Africa.

LAWLOR, G.M. 2008. Examining the fit between personal, learning and practical work contexts of students to further practice excellence in Social Work training. Pretoria: University of South Africa. (Dissertation of limited scope for the MA Social Sciences (Mental Health) at the Department of Social Work)

LINTVELT, R.A. 2008. The personal contexts of undergraduate students in Social Work at UNISA. Pretoria: University of South Africa. (Dissertation of limited scope for the MA Social Sciences (Mental Health) at the Department of Social Work)

LOUW, H. \& DICKER, J. 2001. Community work. Only study guide for SCK3039. Pretoria: University of South Africa.

MBEDZI, R.P. 2009a. General information, curriculum, study material, workshop dates and assignment. Tutorial letter 101/2009 for SCK103Y. Pretoria: University of South Africa.

MBEDZI, R.P. 2009b. Assignment 02: practica tasks and workbook. Tutorial letter 102/2009 for SCK103Y. Pretoria: University of South Africa.

MBEDZI, R.P. 2010. Exploring social workers' integration of the Person-Centred Approach into practice within different working contexts. Pretoria: University of South Africa. (Dissertation of limited scope for the MA Social Sciences (Mental Health) at the Department of Social Work)

MOHAPI, B.J. 2009. Manual for practical group work. Tutorial letter 501/2009 for SCK404D. Pretoria: University of South Africa.

MOHAPI, B.J. \& SCHENCK, C.J. 2006a. Facilitating communication with people in groups and communities. Only study guide for SCK2013. Pretoria: University of South Africa.

MOHAPI, B.J. \& SCHENCK, C.J. 2006b. Practical guide to facilitating communication in groups and communities. Only study guide for SCK2024. Pretoria: University of South Africa.

MOSES, J.W. \& KNUTSEN, T.L. 2007. Ways of knowing: competing methodologies in social and political research. New York: Palgrave MacMillan.

PETTY, A. 2006. Marriage guidance: facilitative couples counselling. Only study guide for MGG201W. Pretoria: University of South Africa.

RSA (REPUBLIC OF SOUTH AFRICA). 1997. Ministry of Welfare and Population Development. White Paper for Social Welfare. Notice 1108 of 1997, Government Gazette, vol. 386, No. 18166 of 8 August. Pretoria, Government Printers.

SCHENCK, C.J. 2002. Practical casework: working with individuals and families. Only study guide for SCK402B. Pretoria: University of South Africa.

SCHENCK, C.J. 2008. Should being a South African make social work training different? Towards giving new meaning to the concept "student-centredness". Unpublished inaugural lecture 21/10/2008: Unisa.

SCHENCK, C.J. 2009. Fourth year overview. Tutorial letter 302/2009 for SCK4009. Pretoria: University of South Africa. 
SKHOSANA, R.M. 2009. Guide for practical community work. Tutorial letter 501/2009 for SCK305B. Pretoria: University of South Africa.

SOCIAL WORK. 2010. Welcome to the Department of Social Work. Home page. [Online]

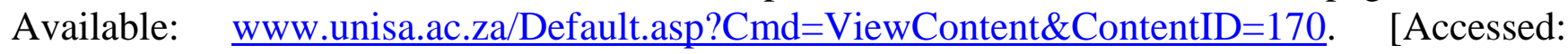
24/09/2010].

STUDENT SYSTEM. 2010. Registrations per subject. [Online] Available: www.unisa. staffonline.ac.za. [Accessed: 03/05/2010].

STUDENT SYSTEM. 2011. Registrations per subject. [Online] Available: www.unisa. staffonline.ac.za. [Accessed: 03/05/2011].

TERRE BLANCHE, M \& DURRHEIM, K. (eds) 2002. Research in practice: applied methods for the social sciences. Cape Town: UCT Press.

UNISA EXAMINATIONS. 2009. Statistical analysis - October/November 2009. Pretoria: Department of Social Work.

UNISA. nd. University of South Africa - the freedom of learning. Pretoria: Studio $M$.

UNISA. nd. 2015 Strategic Plan: an agenda for transformation. [Online] Available: WwW.unisa.staffonline.ac.za. [Accessed: 18/08/2010].

UNISA. nd. Institutional Operational Plan 2010. [Online] Available: www.unisa. staffonline.ac.za. [Accessed: 18/08/2010].

UNISA. 2010. Diversity of learners. [Online] Available: www.unisa.ac.za. [Accessed: 25/08/2010).

UNISA. 2005. Tuition Policy. [Online] Available: www.unisa.staffonline policies. [Accessed: 11/09/2010].

UNISA. 2008. UNISA Open Distance Learning Policy. [Online] Available: WWW.unisa.staffonline policies. [Accessed: 11/08/2010].

VAN DYK, A.C. 2000. Introduction to social work and the helping process. Only study guide for SCK102X. Pretoria: University of South Africa.

VAN DYK, A.C. 2006. Welfare policy. Only study guide for SCK101W. Pretoria: University of South Africa.

VAN DYK, AC \& HARRISON, E. 2008. Social work, supervision and ethics. Only study guide for SCK411C. Pretoria: University of South Africa.

VAN DYK, A.C. 2009. Personal interview - History of the Department of Social Work. 10 May 2009.

WADE, B.L. 2009. UNISA Social Work students' experiences of trauma: and exploratory study from a Person-Centred perspective. Pretoria: University of South Africa. (Thesis submitted for the requirement of the DPhil in Social Work)

ZIMA, P.V. 2007. What is theory? Cultural theory as discourse and dialogue. London: Continuum International Publishing Group.

Prof Desirée de Kock, Department of Social Work, UNISA, Pretoria, South Africa. 